\title{
Consanguinity between Parents and Risk of Epilepsy among Children in Northern Saudi Arabia
}

Yasir Wadi Alanazi ${ }^{1}$, Nagah Mohamed Abo El-fetoh ${ }^{2}$, Ibrahim Meqbel Alanazi ${ }^{1}$, Ahmad Mohammed Masarit ${ }^{3}$, Njood Waleed Nazer ${ }^{4}$, Sulafa Taher Sindi ${ }^{4}$, Muneera Abdulkarim Aldaham ${ }^{1}$, Manal Nashi Alshammari ${ }^{1}$, Nouf Saad Alanazi ${ }^{1}$, Asrar Ali Jabrah ${ }^{3}$, Mohammed Mahmoud Alkhayr ${ }^{5}$, Hisham Hamad Alameer ${ }^{6}$

${ }^{1}$ Faculty of Medicine, Northern Border University, ${ }^{2}$ Community Medicine Department, Faculty of Medicine, Sohag University, Sohag, Egypt And Northern Border University, Arar,

${ }^{3}$ Primary Health Care Center, Jeddah, ${ }^{4}$ King Abdulaziz University (KAU), Jeddah,

${ }^{5}$ King Khaled University, Riyadh, ${ }^{6}$ University of Debrecen, Hungary

\section{ABSTRACT}

Background: Epilepsy is one of the most common neurological disorders in childhood. There are various risk factors that could lead to epilepsy. However, a few studies have shown that there is a strong link between epilepsy and consanguinity. Further, population studies revealed an increased familial clustering of epilepsy among first degree and to a lesser extent second degree relatives. Aim of the work: This study was conducted to determine the prevalence of epilepsy among school children and adolescents (6-18 years) in Northern Saudi Arabia and consanguinity between parents. Methods: A cross-sectional study was conducted among a sample of students aged 6-18 years in all primary, preparatory, and secondary schools in Northern Saudi Arabia, KSA during the academic year 2016-2017. Parents of the studied cases were given a predesigned and pretested questionnaire to collect the relevant data on presence of physicians diagnosed epilepsy, consanguinity between parents and family history of epilepsy. Results: Consanguinity between parents was significantly associated with the development of epilepsy where $59.1 \%$ of epilepsy patients who participated in the current study had parents who were cousins and $13.6 \%$ were non-relatives of the same family and only $22.7 \%$ of cases had no relation between their parents $(\mathrm{p}=0.000)$. Family history of epilepsy was significantly associated with the development of it where $68.2 \%$ of epilepsy patients who participated in the current study had positive family history, while about half of them (31.8\%) had negative family history $(\mathrm{p}=0.000)$. Conclusion: Consanguinity between parents was significantly associated with the development of epilepsy in Northern Saudi Arabia. Decision makers must regulate effective health education sessions to aware the public about consanguinity between parents as a significant risk factor of the epilepsy.

Keywords: Consanguinity between parents, Risk factor, Epilepsy, Northern Saudi Arabia

\section{INTRODUCTION}

Consanguinity is a common marital habit practiced in many developing countries. It is defined as unions contracted between persons biologically related as second cousins or closer ${ }^{[1]}$. Worldwide, 690 million people are consanguineous ${ }^{[2]}$. Up to $50 \%$ of marriages in Arab countries are consanguineous ${ }^{[3]}$. In contrary, many developed countries like USA both second degree and third degree marriages are restricted by law. In Saudi Arabia, reports showed high rates of consanguineous marriage across regions ${ }^{[4]}$, which was associated with mental retardation, neural tube defects and other hereditary neurological diseases ${ }^{[5,}$ 6]. The health complications that are associated with consanguinity are caused by the expression of recessive genes inherited from a common ancestor ${ }^{[7]}$. Further population studies revealed an increased familial clustering of epilepsy among first degree and to a lesser extent, second degree relatives ${ }^{[8]}$. Epilepsy is defined as a chronic neurological condition characterized by recurrent seizures that are caused by abnormal cerebral nerve cell activity and has a very high incidence all across the world.
It is not associated with a high mortality rate ${ }^{[9]}$. Several types of childhood epilepsy, such as benign focal childhood epilepsy, childhood absence epilepsy, and juvenile myoclonic epilepsy, may be passed on from parent to child ${ }^{[10]}$ and the person's risk of developing the disorder partly depends on what type of epilepsy the family member has had. There are various risk factors that could lead to epilepsy. However, a few studies have shown that there is a strong link between epilepsy and consanguinity and with family history. Increased risk of epilepsy at least by 2.2 folds has been also reported after familial marriages in a study from Iran. Another study in Qatar showed that mental retardation and epilepsy were significantly more common in offspring of consanguineous couples [11]. In this study we had investigated the role of parental consanguinity and the risk of epilepsy among siblings and children and the role of previous family history in the disorder's developing.

\section{Objective}

This study was conducted to determine the prevalence of consanguinity between parents among 
physicians diagnosed epilepsy in school children and adolescents (6-18 years) in Northern Saudi Arabia.

\section{METHODS}

A cross-sectional study was conducted among a sample of pupils aged 6-18 years in all primary, preparatory and secondary schools in Northern Saudi Arabia, KSA during the academic year 2016-2017. The sample size was calculated using the sample size equation $n=z^{2} * p(1-p) / e^{2}$ considering the prevalence of epilepsy $50 \%$, and consanguinity between parents $50 \%$, target population more than 1000 and study power $95 \%$.

Data collection: Parents of the studied cases were given a predesigned and pretested questionnaire to collect the relevant data on presence of physicians diagnosed epilepsy, consanguinity between parents and family history of epilepsy.

Ethical considerations: Approval was granted by the Northern Border University Research and Ethics Committee, The Ministry of Health and the Ministry of Education, Arar city. Verbal consent was obtained from headmasters after the aim of the study had been explained. Consent was also obtained from the parents of the study pupils. Confidentiality was ensured at all stages.

\section{Statistical Analysis}

We utilized the Statistical Package for Social Sciences (SPSS Inc., Chicago, IL, USA) version 16 to analyze the study data. Results are displayed as counts and percentages. The chi square and independent sample $t$ tests was used as a tests of significance, and differences were considered significant at $P$ value less than 0.05 .

\section{RESULTS}

Figure (1) shows that; $5.5 \%$ of the studied school children had epilepsy.

Table (1) shows the relationship between epilepsy and consanguinity between parents and family history of epilepsy among studded children. It is clear from the table that, consanguinity between parents was significantly associated with the development of epilepsy where $59.1 \%$ of epilepsy patients who participated in the current study had parents who were cousins and $13.6 \%$ were non-relatives of the same family and only $22.7 \%$ of cases had no relation between their parents $(\mathrm{p}=0.000)$. Family history of epilepsy was significantly associated with the development of it where $68.2 \%$ of epilepsy patients who participated in the current study had positive family history while about half of them (31.8\%) had negative family history $(\mathrm{p}=0.000)$.

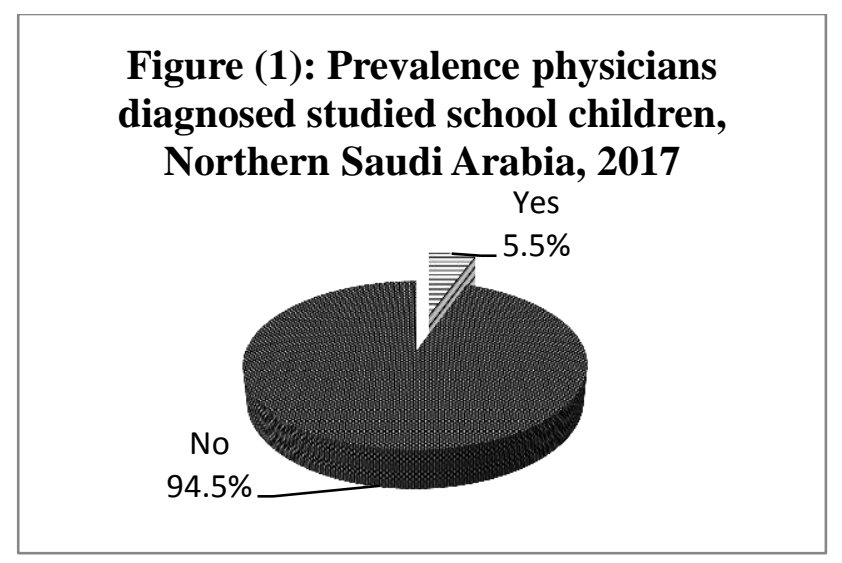

Table (1): Relationship between epilepsy and consanguinity between parents and family history of epilepsy among studded children, northern Saudi Arabia, 2016.

\begin{tabular}{|c|c|c|c|c|c|}
\hline \multirow[t]{2}{*}{ Consanguinity between parents } & \multicolumn{2}{|c|}{ Epilepsy } & \multirow{2}{*}{$\begin{array}{l}\text { Total } \\
(\mathrm{n}=1230)\end{array}$} & \multirow[t]{2}{*}{ Chi square } & \multirow[t]{2}{*}{ alue } \\
\hline & $\begin{array}{l}\text { Yes } \\
(\mathrm{n}=66)\end{array}$ & $\begin{array}{l}\text { No } \\
(n=1164)\end{array}$ & & & \\
\hline \multirow[t]{2}{*}{ Cousins } & 39 & 414 & 453 & \multirow{8}{*}{26.81} & \multirow{8}{*}{01} \\
\hline & $59.1 \%$ & $35.6 \%$ & $36.8 \%$ & & \\
\hline \multirow[t]{2}{*}{ Relatives of the same family } & 3 & 369 & 372 & & \\
\hline & $4.5 \%$ & $31.7 \%$ & $30.2 \%$ & & \\
\hline \multirow{2}{*}{ Non-relatives of the same family } & 9 & 96 & 105 & & \\
\hline & $13.6 \%$ & $8.2 \%$ & $8.5 \%$ & & \\
\hline \multirow[t]{2}{*}{ No relation } & 15 & 285 & 300 & & \\
\hline & $22.7 \%$ & $24.5 \%$ & $24.4 \%$ & & \\
\hline \multicolumn{6}{|l|}{ Family history of epilepsy } \\
\hline \multirow[t]{2}{*}{ Yes } & 45 & 117 & 162 & \multirow[t]{4}{*}{1.84} & \multirow[t]{4}{*}{01} \\
\hline & $68.2 \%$ & $10.1 \%$ & $13.2 \%$ & & \\
\hline \multirow[t]{2}{*}{ No } & 21 & 1047 & 1068 & & \\
\hline & $31.8 \%$ & $89.9 \%$ & $86.8 \%$ & & \\
\hline
\end{tabular}




\section{DISCUSSION}

Epilepsy is one of the most common neurological disorders in childhood ${ }^{[12]}$. The cumulative lifetime incidence of epilepsy is $3 \%$ and more than half of the cases begin in childhood ${ }^{[13]}$. About 69 million people worldwide are affected by this disorder with 90 percent of these individuals living in low- and middleincome countries ${ }^{[14]}$. There are various risk factors that could lead to epilepsy. However, a few studies have shown that there is a strong link between epilepsy and consanguinity. Further, population studies revealed an increased familial clustering of epilepsy among first degree and to a lesser degree second degree relatives ${ }^{[15]}$.

This is A cross-sectional study was conducted among a sample of pupils aged 6-18 years in all primary, preparatory and secondary schools in Northern Saudi Arabia, during the academic year 2016-2017. This study was conducted to determine the prevalence of consanguinity between parents among physicians diagnosed epilepsy in school children and adolescents (6-18 years) in Arar city, Northern Saudi Arabia. Our study reported $5.5 \%$ of the studied group of school children had epilepsy. According to the Relationship between epilepsy and consanguinity between parents, this study reported $36.8 \%$ of the parents were cousins, $59.1 \%$ of them had a child or more with epilepsy. $8.5 \%$ of the parents had non relatives of the same family, $13.6 \%$ of them had epilepsy. We also found that; $22.7 \%$ of the epileptic children had no relation between their parents.

A case control study was conducted among school students aged 6 up to 18 years in Abha and Khamis Mushait in Aseer Region - Kingdom of Saudi Arabia reported $19.4 \%$ of epileptic children had positive consanguineous marriage between their parents ${ }^{[16]}$, This similar to Nermin study ${ }^{[17]}$, but lower than Shawki study ${ }^{[18]}(64.9 \%)$ who attributed this high percent to the prevalent habit of consanguineous marriage in upper Egypt, especially in rural areas and the nature of field study. A retrospective analysis of 740 patients with epilepsy evaluated in Aseer Central Hospital, Abha, Saudi Arabia showed, Parental consanguinity of both degrees was documented in $24 \%$ of the patients (183 cases), where 13\% (97 patients) had first degree PC and 12\% (86 patients) had parents with second degree PC ${ }^{[19]}$.

In Shiraz, Iran, another study conducted among 181 unrelated epileptic children, $61(33.7 \%)$ of the parents were first cousins, $37(20.4 \%)$ were second cousins and $83(45.9 \%)$ were not related ${ }^{[20]}$ and this indicate that the percentage of consanguinity in parents of the epileptic patients was significantly higher in comparison to a sample of the general population $(\mathrm{P}<0.0001)$, which signifies the importance of consanguinity as a potential risk factor for epilepsy ${ }^{[20]}$. Another study conducted among 316 epilepsy sufferers of Indian origin in Malaysia showed that $29.5 \%$ of them had a parental consanguineous marriage ${ }^{[21]}$, For the idiopathic epilepsy group, the rate of epilepsy with consanguineous parental marriage was $9.8 \%$ as compared to $3.7 \%$ with non-consanguineous marriage, For the cryptogenic epilepsy group, the rate of epilepsy with consanguineous parental marriage was $13.3 \%$ as compared to $4 \%$ for non consanguineous marriage ${ }^{[21]}$.

Another study showed a positive history of consanguinity among $17 \%$ of the cases who had epilepsy ${ }^{[22]}$. In Oran, Algeria a case-control study among 101 cases reported first-degree of consanguinity as a factor significantly associated with epilepsy ${ }^{[23]}$. According to family history our study detected in $13.2 \%$ of the total cases, $68.2 \%$ of them was also positive to epilepsy. Another study reported $28.2 \%$ of the cases had positive family history of epilepsy ${ }^{[16]}$, this nearly similar to the studies of Nermin ${ }^{[17]}$ and Ali 25\%, (24\%, and 22.5\%) respectively. Another study reported $56.6 \%$ of the epileptic patients had a positive family history of epilepsy ${ }^{[22]}$.

\section{CONCLUSION AND RECOMMENDATIONS}

Consanguinity between parents was significantly associated with the development of epilepsy in Northern Saudi Arabia. Decision makers must regulate effective health education sessions to aware the public about consanguinity between parents as a significant risk factor of the epilepsy.

\section{Conflict of Interest}

There is no conflict of interest to be declared.

\section{ACKNOWLEDGMENTS}

Authors want to thank Osama Alsallum Alanazi, Alanazi, Ahmed Nidaa $\mathrm{K}$ and Reem Mudhhi Essa Alanazi (Faculty of medicine, Northern border university) and Islam Ahmed Mohamed Azab for continues help in different steps of the research.

\section{REFERENCES}

1. Rehder C, David K, Hirsch B et al. (2013): American College of Medical Genetics and Genomics: standards and guidelines for documenting suspected consanguinity as an incidental finding of genomic testing. Genetics in medicine: official 
journal of the American College of Medical Genetics, 15(2): 150-152.

2. Bittles A and Black M (2010): Evolution in health and medicine Sackler colloquium: consanguinity, human evolution, and complex diseases. Proc Natl Acad Sci U S A., 107:1779-1786

3. Tadmouri G, Nair P, Obeid T et al. (2009): Consanguinity and reproductive health among Arabs. Reprod Health, 6:17

4. El-Hazmi M, al-Swailem A, Warsy A et al. (1995): Consanguinity among the Saudi Arabian population. Journal of medical genetics, 32(8):623-626.

5. Hamamy H, Antonarakis S, Cavalli-Sforza L et al. (2011): Consanguineous marriages, pearls and perils: Geneva International Consanguinity Workshop Report. Genetics in medicine: official journal of the American College of Medical Genetics, 13(9): 841-847.

6. Machado T, Bomfim T, Souza L et al. (2013): Types of marriages, population structure and genetic disease. Journal of biosocial science, 45(4):461-470.

7. Khan H, Mohamed A, Al-Sakini Z et al. (2012): Consanguinity, family history and risk of epilepsy: A case control study:. Gulf Medical Journal, 1(1):3236.

8. Vadlamudi L, Andermann E, Lombroso C et al. (2004): Epilepsy in twins. Neurology, 62: 1127-1133

9. World Health Organization (2011): Fact sheet N999. Epilepsy. Geneva: World Health Organization. Available from: URL: http://www.who.int/mediacentre/factsheets/fs999/en/.

10. Ottman R, Lee J, Risch $\mathbf{N}$ et al. (1996): Clinical indicators of genetic susceptibility to epilepsy. Epilepsia, 37: 353-361.

11. Jain $S$ (2011): Consanguinity and inherited epilepsies. Neurology Asia, 16:11-12.
12. Hauser W (1994): The prevalence and incidence of convulsive disorders in children. Epilepsia, 35: S1-S6

13. Johnston M (2004): Seizures in Childhood, Nelson textbook of pediatrics (17th ed.), Saunders, Philadelphia. pp. 1993-2005

14. Ngugi A, Bottomley $\mathrm{C}$, Kleinschmidt $\mathrm{I}$ et al. (2010): Estimation of the burden of active and lifetime epilepsy: a meta-analytic approach. Epilepsia, 51(5):883-890.

15. Ottman R, Lee J, Risch $\mathbf{N}$ et al. (1996): Clinical indicators of genetic susceptibility to epilepsy. Epilepsia, 37:353-361.

16. Rabie F, Al Asmari A, Al-Barak S et al. (2016): Prevalence and Determinants of Epilepsy among School Children in Aseer Region- KSA. Journal of Education and Practice, 7(21):112-119.

17. Nermin A (2009): Prevalence of Epilepsy in Primary School Children in El-Minia City, Egypt. Egypt J.Neurol. Psychiat. Neurosurg., 46(1): 33-39

18. Shawki O (1996): Clinico- Epidemiologic study of Epilepsy in Assiut. Neuroepidemiology, 12:164-178

19. Fawzi A and Babtain B (2014): Marital Habits Affect Epilepsy Classifications and Etiologies? Update from Epilepsy Registry. American Journal of Medicine and Medical Sciences, 4(3): 96-101

20. Ali Akbar A and Asadi-Pooya (2005): Epilepsy and consanguinity in Shiraz, Iran. European Journal of Paediatric Neurology, 9(6):233-239

21. Ramasundrum V and Tan C (2004): Consanguinity and risk of epilepsy. Neurol Asia , 9: 10-11.

22. Khan H, Mohamed A, Al-Sakini Z et al. (2012): Consanguinity, family history, and risk of epilepsy: A case control study. Gulf Medical Journal, 1(1):32-36.

23. Chentouf A, Talhi R, Dahdouh A et al. (2015): Consanguinity and epilepsy in Oran, Algeria: A casecontrol study. Epilepsy Res., 111:10-7. 